\title{
A Postharvest Fruit Rot Caused by Alternaria sp. on Imported Plum Tomatoes in South Florida ${ }^{1}$
}

\author{
Zelalem Mersha, Shouan Zhang,and Jerry A. Bartz ${ }^{2}$
}

\section{Introduction}

Tomato (Solanum lycopersicum L.) is a highly cherished solanaceous crop native to the west coast of South America in the area of Peru and Ecuador (Olson et al. 2012). The United States is the second largest producer of tomato in the world with estimated annual farm income of $\$ 2$ billion (USDA-ERS 2012). Florida and California account for two-thirds to three-fourths of all commercially produced fresh-market tomatoes in the United States. In 2009, about 105,700 acres were harvested with a production of 32,365,000 hundredweight (cwt = $100 \mathrm{lb}$.) (USDA-ERS 2010). In Florida, the average tomato yield is about 1,400 25-pound cartons per acre (Olson et al. 2012). Since production in the United States does not fully satisfy domestic consumption, tomato imports increased from one-fifth in the early 1990s to one-third by 2012 .

Florida's deep-water ports are ideal for importing many fruits and vegetables, including tomatoes, by ship from the Caribbean as well as Central and South American production areas. These imports are often strictly regulated for pests, but some pathogens still escape quarantine. This publication describes a postharvest problem on plum tomatoes that were imported from Mexico through South Florida in 2010. Alternaria sp. was isolated from lesions on diseased fruits, pathogenicity tests were conducted on healthy fruits, and symptoms identical to the originally submitted samples were developed.

\section{Brief background}

Tomato fruits with dark sunken lesions were brought to the Plant Diagnostic Clinic at the Tropical Research and Education Center (TREC) in Homestead, Florida, on June 25, 2010 (Fig. 1). Initial incidence of symptomatic fruits was estimated to be $25 \%$. Based on the literature, the disease was tentatively identified as black mold rot (Bartz, Sargent, and Gilreath 2007; Bartz, Sargent, and Mahovic 2009; Jones et al. 1991; Koike, Gladders, and Paulus 2006). Observations of hyphae, conidiophores, and conidia supported the initial diagnosis.

\section{Isolation of pathogenic organisms on APDA and microscopic observations}

Molten potato dextrose agar was amended with $0.1 \mathrm{~g} / \mathrm{L}$ lactic acid (called APDA), $100 \mathrm{mg} / \mathrm{L}$ streptomycin, and $250 \mathrm{mg} / \mathrm{L}$ ampicillin, then poured into Petri dishes. Small pieces of fruit tissue were cut from the advancing margin of lesions, disinfected in $70 \%$ ethanol for $15-30$ seconds followed by $10 \%$ Clorox $^{\oplus}$ solution for 2 minutes, placed on the surface of the APDA-antibiotic medium, and incubated

1. This document is PP303, one of a series of the Plant Pathology Department, Florida Cooperative Extension Service, Institute of Food and Agricultural Sciences, University of Florida. Original publication date January 2013. Visit the EDIS website at http://edis.ifas.ufl.edu.

2. Zelalem Mersha, former postdoctoral associate, Plant Pathology Department, Tropical Research and Education Center, Homestead, FL; currently, assistant professor/state plant pathology specialist, Lincoln University Cooperative Extension, Jefferson City, MO; Shouan Zhang, assistant professor, Plant Pathology Department, Tropical Research and Education Center, Homestead, FL; and Jerry A. Bartz, associate professor, Plant Pathology Department, Gainesville, FL, Florida Cooperative Extension Service, Institute of Food and Agricultural Sciences, University of Florida, Gainesville, FL 32611. 

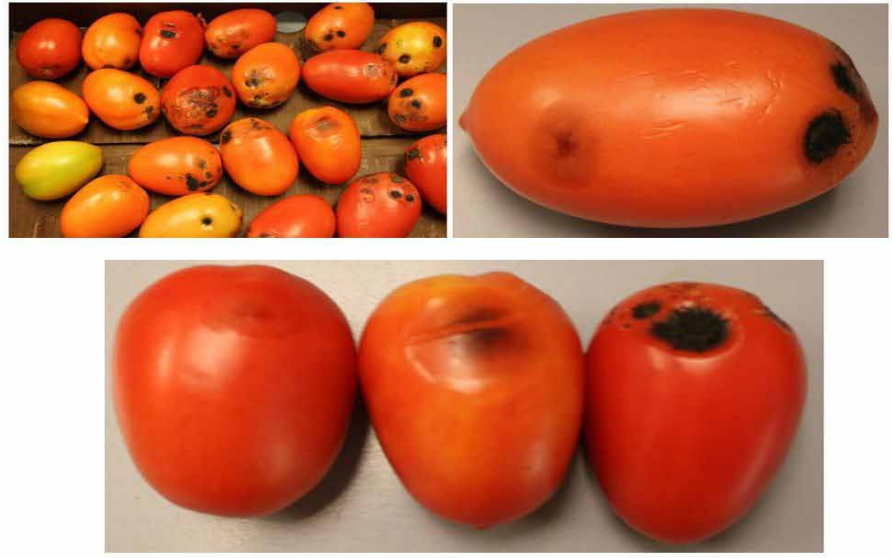

Figure 1. a) Diseased tomato fruits while in the shipping container (top left), b) individual fruit with early and late symptoms (top right), and c) symptoms starting as circular water-soaked areas through development into sunken black cups and cracks (bottom).

Credits: Z. Mersha

at $25^{\circ} \mathrm{C}$. Fungal colonies began developing within $24-48$ hours. The shape and color of the colonies were consistent with Alternaria sp. (Fig. 2). Fungal structures observed under a compound microscope were also consistent with those reported for Alternaria sp. (Fig. 3). The average dimension of conidia was $43.3(39.6-46.2) \times 10.8(9.9-12.1)$ $\mu \mathrm{m}$.

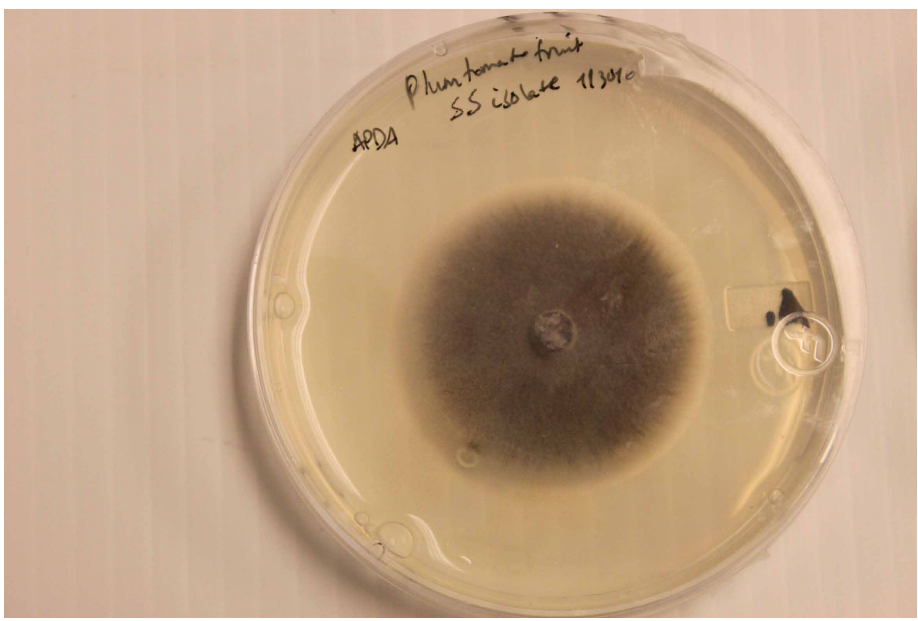

Figure 2. A week-old colony of the isolated fungus (Alternaria sp.) on APDA.

Credits: Z. Mersha

\section{Tests on pathogenicity of the isolate}

Sound red (with no cracks or bruises on the surface) plum tomato fruits were purchased from a supermarket in Homestead, Florida, dipped into $10 \%$ Clorox $^{\circledast}(0.6 \%$ $\mathrm{NaOCl}$ ) for 30 seconds and air dried under ambient conditions in a laminar flow cabinet for 10 minutes. Inoculum was prepared by cutting a 2 -week-old culture in half, placing one half in $100 \mathrm{ml}$ sterile distilled water, and

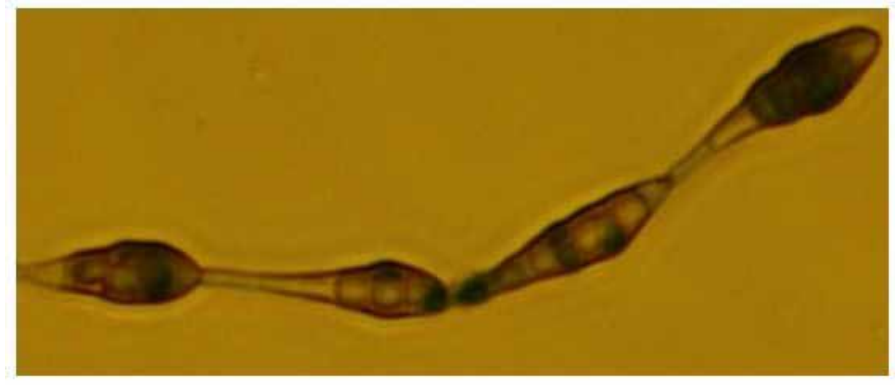

Figure 3. A chain of conidia produced by Alternaria sp. isolated from imported Mexican plum tomatoes ( $400 \times$ magnification).

Credits: Z. Mersha

brushing the culture surface. The resulting suspension was filtered through three layers of cheese cloth. The filtered suspension contained $8.6 \times 10^{4}$ conidia $/ \mathrm{ml}$ based on counts under a microscope with a haemocytometer. Tomato fruits were gently pierced using sterile Eppendorf pipette tips, and $10 \mu \mathrm{l}$ of the aqueous conidial suspension was deposited on the wound. Fruits were carefully placed in white plastic bags and incubated under laboratory conditions $\left(\sim 22^{\circ} \mathrm{C}\right.$ $\left.-24^{\circ} \mathrm{C}\right)$.

Slightly sunken spots with a faint blackish center were observed at the inoculated wound sites about 4 days after inoculation (Fig. 4). After 7 days, lesions were enlarged with black signs of the causal agent appearing in the wound. Subsequently, some of the lesions coalesced, leading to a large area of decay. However, the wounded control fruits did not develop lesions, even though nearby inoculated fruit had lesions with clear evidence of sporulation beginning at 7-10 days. With red plum tomatoes, infection by Alternaria sp. could start as early as 4 days after inoculation and progress very rapidly, depending on fruit integrity, extent of bruises/damage from packing or transportation, inoculum availability, and bruises, wounds, or any type of crack.

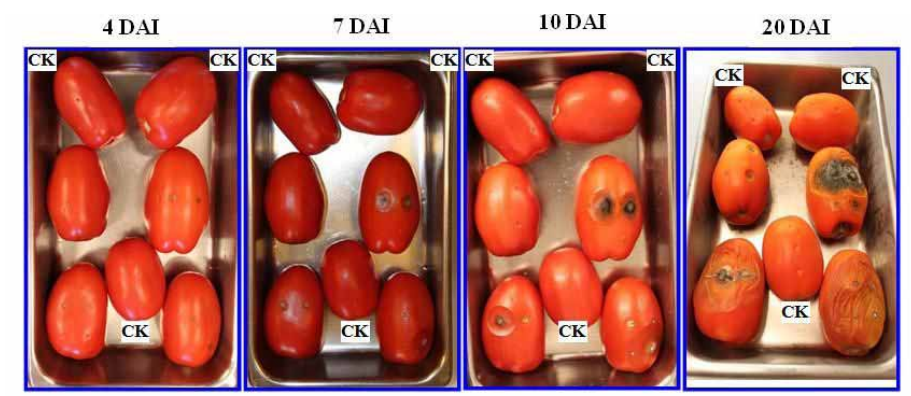

Figure 4. Pathogenicity test of the isolated Alternaria sp. on plum tomatoes and symptom development at 4, 7, 10, and 20 days after inoculation (DAI). Note: Two of the plum tomato fruits on top and one of them in the middle were untreated control (CK) (i.e., inoculated with deionized water).

Credits: Z. Mersha 


\section{Management}

Based on descriptions of black mold rot in the literature, importers should carefully inspect tomato lots prior to accepting them. The Alternaria pathogen is an opportunistic wound invader that can infect physical and developmental wounds such as necrotic tissues from blossom end rot, sunscald, heat injury, shoulder cracks, cuticle cracks, and/ or harvest-related wounds. Fruits exposed to chilling temperatures, whether in field, in storage, or in both places, are also predisposed to this disease. Integrated control for black mold rot includes culling damaged or visibly infected fruit, avoiding harvest or production practices that damage fruit, and maintaining sanitary conditions around the packinghouse. During periods of high temperatures, commercial products are available that can be applied to exposed fruit surfaces to reduce heat injury and sunscald. Cultural practices that encourage canopy development help to prevent fruit from being exposed to direct sunlight. Balanced irrigation is essential to preventing blossom end rot and reducing fruit cracking. Foliar diseases must be controlled since leaf abscission exposes fruit to sunlight and reduces transpiration; reduced transpiration, with or without excessive irrigation, leads to cracking of tomato fruits.

\section{References}

Bartz, J. A., S. A. Sargent, and P. R. Gilreath. 2007. Critical Issues for the Tomato Industry: Preventing a Rapid Postharvest Breakdown of the Fruit. HS1107. Gainesville: University of Florida Institute of Food and Agricultural Sciences. http://edis.ifas.ufl.edu/hs363.

Bartz, J. A., S. A. Sargent, and M. Mahovic. 2009. Guide to Identifying and Controlling Postharvest Tomato Diseases in Florida. HS866. Gainesville: University of Florida Institute of Food and Agricultural Sciences. http://edis.ifas.ufl.edu/ hs131.

Jones, J. P., R. E. Stall, and T. A. Zitter. 1991. Compendium of Tomato Diseases. St. Paul, MN: APS Press.

Koike, T. S., P. Gladders, and O. A. Paulus. 2006. Vegetable Diseases: A Colour Handbook. Burlington, MA: Academic Press.

Olson, S. M., P. J. Dittmar, G. E. Vallad, S. E. Webb, S. A. Smith, E. J. McAvoy, B. M. Santos, and M. OzoresHampton. 2012. Tomato Production in Florida. HS739. Gainesville: University of Florida Institute of Food and Agricultural Sciences. http://edis.ifas.ufl.edu/cv137.
United States Department of Agriculture, Economic Research Service (USDA-ERS). 2010. U.S. Tomato Statistics (92010). http://usda.mannlib.cornell.edu/usda/ers/92010/.

United States Department of Agriculture, Economic Research Service (USDA-ERS). 2012. Vegetables \& Pulses: Tomatoes. http://www.ers.usda.gov/topics/crops/vegetablespulses/tomatoes.aspx. 